\title{
Effects of Obesity and Spirometric Ventilatory Status in Male Medical Students of Amritsar
}

\author{
Shashi Mahajan ${ }^{1}$, Gurmehar S Hundal ${ }^{2}$, Anterpreet K Arora ${ }^{3}$, Pankaj Gupta ${ }^{4}$
}

\begin{abstract}
Aim and objective: To study the effects of obesity on the pulmonary functions in male medical students of Amritsar . Materials and methods: Pulmonary function tests (PFTs) of normal, healthy, male medical students of Amritsar were determined and were compared and correlated with other studies. Criteria for obesity in our study taken were according to WHO criteria of BMI. The PFTs were carried out with a computerized spirometer "Med-Spiror". The data were collected; compiled, statistically analyzed, and valid conclusions were drawn. Higher lung volumes and flow rates were achieved.

Results: There was a statistically highly significant decline in forced vital capacity (FVC) in obese when compared with nonobese groups. The values of forced expiratory volume in first second $\left(\mathrm{FEV}_{1}\right)$ in both groups when were compared showed significant changes. The ratio of $\mathrm{FEV} 1 /$ FVC, the values of peak expiratory flow rate (PEFR), and forced mid-expiratory flow $\left(\mathrm{FEF}_{25-75 \%}\right)$ showed insignificant changes but maximum voluntary ventilation (MVV) when were compared showed highly significant changes.

Conclusion: There is a decline of various respiratory functions in obesity. The cause of the decline of various respiratory functions in obesity may be due to a decrease in distensibility of the chest wall or limited expansion of the thoracic cavity and is the cause for reduced ventilatory volumes and total lung capacity.

Keywords: Expiration, Obesity, Medical students, Pulmonary, Pulmonary function test.

AMEl's Current Trends in Diagnosis \& Treatment (2020): 10.5005/jp-journals-10055-0109
\end{abstract}

\section{INTRODUCTION}

There has been an epidemiological transition in the recent past, leading to an increase in noninfectious diseases due to a change in lifestyle, including changes in food consumption patterns. Among these noninfectious diseases, obesity is one of the most important ones. Pulmonary function tests in health are influenced by several factors like age, sex, height, and weight along with various environmental pollutants and genetic, ethnic, socio-economic, and technical variations. Carbon dioxide production increases as a function of body weight. ${ }^{1,2}$

Obesity has reached an epidemic proportion in India in the 21 st century with morbid obesity affecting $5 \%$ of the country's population. ${ }^{3}$ It is a cluster of disease that comprises multiple cardiovascular risk factors, such as insulin resistance, dyslipidemia, glucose intolerance, hypertension, dyslipidemia, type II diabetes mellitus, coronary heart disease, cerebral stroke, gall bladder disease, osteoarthritis, some cancers, ${ }^{4}$ aspiration pneumonia, pulmonary thromboembolism, obstructive sleep apnea, obesity hypoventilation syndrome, and respiratory failure, which are associated with substantial morbidity and increased mortality. ${ }^{5}$ Obese subjects consume approximately $25 \%$ more oxygen than nonobese subjects at rest. The increased lung and respiratory system resistance in obesity are due to the reduction of lung volume. It can diminish exercise capacity by its adverse effects on respiratory mechanics, resistance in the respiratory system, respiratory muscle function, and lung volumes. ${ }^{3}$ Obesity causes airflow limitation with reduction of both forced expiratory volume in first second $\left(\mathrm{FEV}_{1}\right)$ and forced vital capacity (FVC) and reduces lung volumes, especially expiratory reserve volume (ERV), and functional residual capacity (FRC), obstructive sleep apnea, a depressed central ventilatory drive. ${ }^{6}$
${ }^{1}$ Department of Physiology, Shri Guru Ram Das Institute of Medical Sciences and Research, Amritsar, Punjab, India

${ }^{2}$ Government Medical College and Hospital, Chandigarh, Punjab, India ${ }^{3}$ Department of Anatomy, Shri Guru Ram Das Institute of Medical Sciences and Research, Amritsar, Punjab, India

${ }^{4}$ Department of Forensic Medicine, Shri Guru Ram Das Institute of Medical Sciences and Research, Amritsar, Punjab, India

Corresponding Author: Shashi Mahajan, Department of Physiology, Shri Guru Ram Das Institute of Medical Sciences and Research, Amritsar Punjab, India, Phone: +91 9855203124, e-mail: shashimahajan17@ gmail.com

How to cite this article: Mahajan S, Hundal GS, Arora AK, et al. Effects of Obesity and Spirometric Ventilatory Status in Male Medical Students of Amritsar. AMEl's Curr Trends Diagn Treat 2020;4(2):74-77.

Source of support: Nil

Conflict of interest: None

Abdominal obesity has the strongest relationship with pulmonary function deterioration. ${ }^{7,8}$ A pulmonary function test (PFT) is a comprehensive evaluation of the respiratory system. The main purpose of pulmonary function testing is to identify the severity of respiratory impairment. Pulmonary function testing has diagnostic and therapeutic roles and helps clinicians answer general questions about patients with lung disease. Obesity places subjects at the risk of many diseases. ${ }^{8}$

Therefore, in the present study, an attempt was made to examine the effect of obesity in male medical students to body mass index (BMI) on the selected parameters of pulmonary function tests. This study can encourage losing weight to improve their lung functions. Moreover, this research has not been yet done in our setup. 


\section{Material and Methods}

In this cross-sectional case-control study, a total of 200 subjects were studied including 100 nonobese medical male students and 100 obese medical male students (according to WHO criteria of $\mathrm{BMI}]^{9}$ selected from tertiary care medical institute in Amritsar). Overweight and obesity were assessed from BMI, hence BMI can be considered to provide the most useful and dependable indicator of obesity, as other measures of obesity provide additional information rather than primary information. ${ }^{10}$

The subjects were in the age group of 18-23 years (Table 1). In our research, we selected the above-mentioned range of age and this particular sex (males) because in this region of Punjab (Amritsar), the medical male students of this age group have a careless and inappropriate intake of caloric rich easily available junk food and automated working profile with sedentary lifestyle so are more prone to obesity.

Now with the availability of sophisticated and advanced technology the values of pulmonary functions are more reliable. Spirometry is a simple, noninvasive method of assessing pulmonary functions or lung functions. The ventilatory (pulmonary) function tests were done with the help of a PC-based computerized spirometer. This is an advanced accurate microprocessor controlled electron equipment with trade name and model Computerized Spirometer MEDSPIROR RMS CHANDIGARH, INDIA. PLATFORM WIN 98 VERSION 1, which gives much more detailed pulmonary function analyses. The parameters recorded were FVC, FEV 1 , PEFR, $\mathrm{FEF}_{25-75 \%}, \mathrm{FEV}_{1} / \mathrm{FVC}$, and MVV.

Lung functions were carried out in a standing posture. Subjects with any history of smoking, chronic cough, recurrent respiratory tract infection, history of chest or spinal deformity, personal history of asthma, and chronic obstructive lung diseases were excluded from the study. The anthropometric measurements taken on each subject using standard methodology given by Weiner and Lourie were height and weight. Body mass index $=$ weight $(\mathrm{kg}) /$ height $^{2}(\mathrm{~m})$. To assess overweight and obesity WHO (1998) criteria of BMI has been the most accepted criteria all over the world. Subsequently, one more criterion labeled as WHO (2000) criteria of BMI in Asians was introduced in which cut-off for overweight $\left(\geq 23.0 \mathrm{~kg} / \mathrm{m}^{2}\right)$ and obesity $\left(\geq 25.0 \mathrm{~kg} / \mathrm{m}^{2}\right)$ are lower than WHO criteria (1998). In the present study, an attempt was made to select the subjects according to WHO (2000) criteria of BMI, that is, $<18.5$ are underweight, BMI between 18.5 and 22.9 is normal, $>23.0$ are overweight 23-24.9 are at risk, $25-29.9$ are obese-I $\geq 30$ are obese- $-I .{ }^{9} \mathrm{BMI}<23$ is considered normal for urban Indians. ${ }^{11}$ Weighing machine was used for weight measurement and the anthropometric rod was used for the measurement of height. The testing procedures were quite simple and noninvasive and were harmless to the patients. The terminology and abbreviations used for the different parameters suggested by Cotes. ${ }^{12}$

Table 1: Division of sample size

\begin{tabular}{llll}
\hline Groups & Classification & $\begin{array}{l}\text { Number of } \\
\text { subjects }\end{array}$ & $\begin{array}{l}\text { Control/ } \\
\text { obese }\end{array}$ \\
\hline Group A & $\begin{array}{l}\text { Nonobese medical male students } \\
(18-23 \text { years })\end{array}$ & 100 & Control \\
Group B & $\begin{array}{l}\text { Obese medical male students } \\
(18-23 \text { years })\end{array}$ & 100 & Obese \\
\hline
\end{tabular}

\section{Statistical Analysis}

The mean values with a standard deviation of age, a parameter of obesity, that is, BMI, spirometric parameters in the different groups were taken. The " $p$ " and " $t$ " values were determined, $p>0.05$ were considered as non-significant. Data obtained was fed to a computer and analyzed and valid conclusions were drawn.

\section{Results}

The statistical values of forced vital capacity (FVC), FEV 1 , and MVV showed a significant decline in group $B$ when compared with group A (Table 2).

The statistical values of $\mathrm{FEV}_{1} / \mathrm{FVC}$, mean forced expiratory flow during the middle half of the FVC $\left(\mathrm{FEF}_{25-75 \%}\right)$, and peak expiratory flow rate (PEFR) showed insignificant changes in group $B$ when compared with group A (Table 2).

\section{Discussion}

Each spirometric parameter has been dealt with separately explaining the changes in group $B$ obese medical male students (cases) when compared to group A nonobese medical male students (controls).

In the present study, the value of FVC decreases significantly with obesity in medical males. The significant decrease in FVC may be due to elevated diaphragm, mediastinal fat deposition, interfering with the movements of the chest, decreased compliance, and marked thoracic kyphosis. ${ }^{13}$ Similar to our study, there are many corroborative studies.

Ashraf et al., ${ }^{14}$ found a statistically significant decline in FVC with increased obesity. According to the studies by Wang et al., ${ }^{15}$ FVC decreased significantly in obese subjects than in nonobese subjects.

According to the findings of Sorani et al., ${ }^{16}$ FVC, expiratory reserve volume, and maximum voluntary ventilation were significantly decreased in the obese group ( $p<0.001)$.

Chen et al., Lazarus et al., Pankow et al., Chinn et al. have also been reported where FVC decreased significantly with obesity. ${ }^{17-20}$

Contrary to our study, a study by Bhattacharjee et al. showed a significant increase in FVC with obesity. ${ }^{21}$

In the present study, it has been seen that FEV ${ }_{1}$ declined significantly $(p<0.05)$ in group B obese males when compared to group $A$ nonobese males of the same age group. The findings of the present study are in concurrence with that of other studies

Table 2: Respiratory parameters with mean values ( \pm SD) of group Anonobese (controls (18-23 years)) medical male students and group B-obese medical male students (18-23 years)

\begin{tabular}{|c|c|c|c|c|}
\hline & $\begin{array}{c}\text { Group A (Control) } \\
(18-23 \text { years, } \\
n=100) \\
\end{array}$ & $\begin{array}{c}\text { Group B (Obese) } \\
(18-23 \text { years, } \\
n=100) \\
\end{array}$ & & \\
\hline Parameters & Mean $\pm S D$ & Mean $\pm S D$ & t-value & $p$-value \\
\hline FVC & $3.45 \pm 0.50$ & $3.23 \pm 0.40$ & 2.55 & $<0.05^{*} \mathrm{~S}$ \\
\hline $\mathrm{FEV}_{1}$ & $2.80 \pm 0.53$ & $2.60 \pm 0.40$ & 2.23 & $<0.05^{*} \mathrm{~S}$ \\
\hline PEFR & $7.26 \pm 1.64$ & $7.20 \pm 1.12$ & 0.22 & $>0.05 \mathrm{NS}$ \\
\hline $\mathrm{FEF}_{25-75 \%}$ & $3.65 \pm 0.86$ & $3.55 \pm 1.13$ & 0.54 & $>0.05 \mathrm{NS}$ \\
\hline $\mathrm{FEV}_{1} / \mathrm{FVC}$ & $81.35 \pm 13.33$ & $81.42 \pm 8.63$ & 0.33 & $>0.05 \mathrm{NS}$ \\
\hline MVV & $114.83 \pm 23.24$ & $97.64 \pm 33.31$ & 3.27 & $<0.05^{*} \mathrm{~S}$ \\
\hline
\end{tabular}

${ }^{*}$ S, significant $p<0.05 ;$ NS, non-significant $p>0.05$ 
by Chen et al., where with an increase in body weight, a decrease in $\mathrm{FEV}_{1}$ was shown in a six-year follow-up study. ${ }^{22}$ Also in another study by Bottai et al. on longitudinal changes of body mass index, spirometry, and diffusion in a general population, BMI or body weight gains were related to the longitudinal decline of $F E V_{1}$ in adults. ${ }^{23}$ Another similar type of study by Carey et al. showed that weight changes, body mass, waist circumference were all associated with changes in $\mathrm{FEV}_{1}(p<0.001)$. Every $10 \mathrm{~kg}$ weight increase induced an additional fall of FEV ${ }_{1}{ }^{24}$ Other studies by Kharodi et al., Ashraf et al., Biring et al., and Ahmed and Morgan also stated that obesity was associated with a significant decline of $\mathrm{FEV}_{1}{ }_{1}^{3,14,25,26}$

Contrary to our study, a study by Bhattacharjee et al. showed a significant increase in $\mathrm{FEV}_{1}$ with obesity. ${ }^{21}$

In the present study, PEFR declined non-significantly $(p>0.05)$ in group $B$ when compared to group $A$ as shown in Table 2.

Contrary to our study, a study by Bhattacharjee et al. showed a significant increase in PEFR with obesity. ${ }^{21}$

In the present study, the mean forced expiratory flow during the middle half of the FVC $\left(\mathrm{FEF}_{25-75 \%}\right)$ declined non-significantly $(p>0.05)$ in group B obese males when compared to group A as shown in Table 2. Contrary to our study, the research by Biring et al. showed a significant decline in $\mathrm{FEF}_{25-75 \%}$ with obesity. ${ }^{23}$ According to research by Bhattacharjee et al., FVC, FEV 1 , PEFR increases significantly but $\mathrm{FEF}_{25-75 \%}$ decreases significantly. ${ }^{21}$

In the present study, there has been a non-significant $(p>0.05)$ rise in $\mathrm{FEV}_{1} / \mathrm{FVC}$ ratio in group $B$ when compared to group $A$ as shown in Table 2.

Another study showed a similar type of effects of obesity on $\mathrm{FEV}_{1} / \mathrm{FVC}$ at all ages where BMI was positively associated with this ratio $(p<0.01)^{25}$ as shown in Table 2 .

In the present study, MVV declined highly significant $(p<0.001)$ in group B obese males when compared to group $A$ as shown in Table 2. Similar results have been shown by other researchers like Oriel et al., Sorani et al., and Zerah et al., where there was a highly significant decline in MVV in the obese group when compared to the normal group. ${ }^{13,16,27}$

The decline in MVV in obesity may be due to increased tissue resistance, increased intraabdominal pressure in obese persons, and exaggeration of the normal spinal curvature due to forward displacement of the center of gravity of the body, thus causing profound thoracic kyphosis, the elevation of the lower sternum as a result of upward pressure of large abdomen and kyphosis of the thoracic spine, relative fixation of the chest in a position of moderate inspiration so that changes in the lung are brought about almost entirely by diaphragmatic action alone and consequence of reduced ERV. ${ }^{13}$

The decrease in various lung function parameters in obesity has been described by various scientists through different mechanisms. A study by Kharodi et al. revealed a significant decrease in pulmonary function tests in overweight and obese females who do not have any known obstructive airway disease. ${ }^{3}$

The accumulation of fat may mechanically affect the expansion of the diaphragm, probably by encroaching into the chest by the chest wall or diaphragm ${ }^{28}$ or by impending the descent of the diaphragm during forced inspiration. ${ }^{18}$ Low FEV $_{1}$ and FVC values suggest restrictive lung pattern among obese persons. The cause of the decline of various respiratory parameters in obesity may be due to a decrease in dispensability of the chest wall and is the cause for the alterations in ventilatory volume and flow ${ }^{27}$, which may reflect extrinsic mechanical compression on the lung and thorax and/or intrinsic changes within the lung in the form of deranged pulmonary function tests, modifying airway smooth muscle function by obesity-related changes in lung development. This relation between obesity and pulmonary function may also suggest a possible role of obesity in the etiology of mortality, associated with decreased pulmonary function, particularly death related to cardiovascular disease. These detrimental effects of gaining weight might be reversible for many adults, as it was observed that most of those who reduced their BMI values also increased their lung function. This may have important clinical implications, for instance, overweight patients with ventilatory impairment could be routinely encouraged to lose weight to improve their lung function. ${ }^{23}$

\section{Conclusion}

It is evident from the present study that obesity significantly affects pulmonary functions. The cause of decline of various respiratory functions in obesity may be due to a decrease in distensibility of the chest wall or limited expansion of the thoracic cavity and is the cause for reduced ventilatory volumes and total lung capacity. These hazardous effects of gaining weight might be reversible and weight loss can improve lung function in obesity. So, obese patients benefit from weight loss by improved pulmonary mechanics.

\section{ACKNOWLeDgments}

The authors express gratitude to the medical students, technical staff, and helpers of the tertiary care medical institute, Amritsar, Punjab for their involvement in the study.

\section{References}

1. Sharma VK, Garg VK, Parihar HL, et al. Respiratory morbidity and pulmonary function impairment in 'soldiers': an occupational hazard in modern electronics. Lung India 1993;11(4):143-146.

2. Singh SK, Nishith DS, Tandon GS, et al. Some observations of pulmonary function tests in rice mill workers. Indian J Physiol Pharmacol 1988;32(2):152-157.

3. Kharodi C, Goel A, Puri N, et al. Correlation of body mass index with pulmonary function tests in North Indian females. Int J Contemp Med Res 2019;6(3):C10-C12. DOI: 10.21276/ijcmr.2019.6.3.36.

4. NHANES Data on the Prevalence of overweight and obesity among Adults: United States; 2003-2004.

5. Chaudhary SC, Kumari T, Usman K, et al. Study of pulmonary function test abnormalities in metabolic syndrome. J Assoc Physicians India 2018;66(10):27-30.

6. Koenig SM. Pulmonary complications of obesity: a review. Am J Med Sci 2001;321(4):249-279.

7. Yeh F, Dixon AE, Marion S, et al. Obesity in adults is associated with reduced lung function in metabolic syndrome and diabetes: the Strong Heart Study. Diabetes Care 2011;34(10):2306-2313. DOI: 10.2337/dc11-0682.

8. Marcus CL, Curtis S, Koerner CB. Evaluation of pulmonary function and polysomnography in obese children and adolescents. Pediatr Pulmol 1996;21(3):176-183. DOI: 10.1002/(SICI)10990496(199603)21:3<176::AID-PPUL5>3.0.CO;2-O.

9. WHO (1998). Technical Report Series 894. Obesity: preventing and managing the global epidemic. http://www.who.int/nutrition/ publications/obesity/WHO_TRS_894/en/index.html. Accessed on 04 Sep 2020.

10. WHO (2000). World Health Organization. Regional Office for the Western Pacific. (2000). The Asia-Pacific perspective: redefining obesity and its treatment. Sydney: Health Communications Australia. https://apps.who.int/iris/handle/10665/206936. Accessed on 04 Sep 2020. 
11. Snehalatha C, Viswanathan V, Ramachandran A. Cutoff values for normal anthropometric variables in Asian Indian adults. Diabetes Care 2003;26(5):1380-1384. DOI: 10.2337/diacare.26.5.1380.

12. Cotes JE. Lung function assessment and application in medicine, 4 th ed. London; Blackwell Scientific Publishers; 1979. pp. 332-345.

13. Oriel EJ, Vasavada JP, Khanijo SK, et al. Observations on pulmonary functions in obesity. Indian J Chest Dis Allied Sci 1979;21(2): 73-79.

14. Hatem AM, Ismail MS, El-Hinnawy YH. Effect of different classes of obesity on the pulmonary functions among adult Egyptians: a crosssectional study. Egypt J Bronchol 2019;13(4):510-515. DOI: 10.4103/ ejb.ejb_21_19.

15. Wang S, Sun X, Hsia T, et al. The effects of body mass index on spirometry tests among adults in Xi'an, China. Medicine 2017;96(15):e6596. DOI: 10.1097/MD.0000000000006596.

16. Sorani A, Savalia C, Chavda B, et al. Analysis of lung functions in obese young adult male. Int J Basic Appl Physiol 2013;2(1):25-29.

17. Chen $Y$, Rennie D, Cormier $Y F$, et al. Waist circumference is associate $\mathrm{d}$ with pulmonary function in normal-weight, overweight, and obese subjects. Am J Clin Nutr 2007;85(1):35-39. DOI: 10.1093/ ajcn/85.1.35.

18. Lazarus R, Gore CJ, Booth M. Effects of body composition and fat distribution on ventilatory function in adults. Am J Clin Nutr 1998;68(1):35-41. DOI: 10.1093/ajcn/68.1.35.

19. Pankow W, Podszus T, Gutheil T. Expiratory flow limitation and intrinsic positive end expiratory pressure in obesity. J Appl Physiol 1998;85:1236-1243. DOI: 10.1152/jappl.1998.85.4.1236.
20. Chinn DJ, Cotes JE, Reed JW. Longidutinal effects of change in body mass on measurements of ventilatory capacity. Thorax 1996;51:699704. DOI: 10.1136/thx.51.7.699.

21. Bhattacharjee A, Malik T, Myat A, et al. Effect of obesity on pulmonary functions among the adolescent students of a private university in Malaysia. J Clin Diagn Res 2018;12(8):24-27. DOI: 10.7860/ JCDR/2018/36228.12002.

22. Chen Y, Horne SL, Dosman JA. Body weight and weight gain related to pulmonary function decline in adults: a six year follow up study. Thorax 1993;48(4):375-380. DOI: 10.1136/thx.48.4.375.

23. Bottai M, Postello F, Fdi $P$, et al. Longitudinal changes of body mass index, spirometry and diffusion in a general population. Eur Respir J 2002;20:665-673. DOI: 10.1183/09031936.02.01282001.

24. Carey IM, Cook DC, Strachan DP. The effects of adiposity and weight change on forced expiratory volume decline in a longitudinal study of adults. Int J Obes Relat Metab Disord 1999;23(9):979-985. DOI: 10.1038/sj.ijo.0801029.

25. Biring MS, Lewis MI, Liv JT. Pulmonary physiological changes of morbid obesity. Am J Med Sci 1999;318:293-297. DOI: 10.1097/00000441199911000-00002.

26. Ahmed D, Morgan WKC. Obesity and lung function. Thorax 2001;56(9):740-741. DOI: 10.1136/thorax.56.9.740c.

27. Zerah F, Harf A, Perlemuter L, et al. Effects of obesity on respiratory resistance. Chest 1993;103(5):1470-1476. DOI: 10.1378/chest.103.5.1470.

28. Ray CS, Sue DY, Bray G, et al. Effects of obesity on respiratory complication. Am Rev Respir Dis 1983;128(3):501-506. DOI: 10.1164/ arrd.1983.128.3.501. 